\title{
The Repercussions of Assessment on the Teaching and the Learning Process
}

\author{
Mahmoud Sultan Nafa \\ City University College of Ajman, Ajman, United Arab Emirates
}

\begin{abstract}
This paper explores profoundly the pivotal role that assessment plays in the educational process from different perspectives. Firstly, it defines the concept of assessment and points out the differences between assessment and evaluation. Moreover, it explicates the impacts of assessment on the educational process and investigates the different levels of assessment and the role of each level in enriching the educational process. Furthermore, it states the characteristics of an effective and efficient assessment tool, and the practical ways of designing and implementing exams in a constructive and engaging educational environment. Additionally, this article differentiates between assessments in order to make use of them effectively.
\end{abstract}

Keywords: lower order thinking skills (LOTS), interim assessment, validity, reliability, scorability

\section{Introduction}

Assessment plays a decisive role in the whole educational process although it occupies the third position in the educational circle arrangement (see Figure 1) after the behavioral objectives, the teaching techniques, and activities. Moreover, it has a preponderant effect on the teaching staffs' and learners' psychological and professional development as well as their teaching and learning styles. Additionally, assessment determines the choice and the functions of leadership and management at the educational establishment as it is the gauge of their success, efficiency and productivity. Thus, this article will answer the following questions.

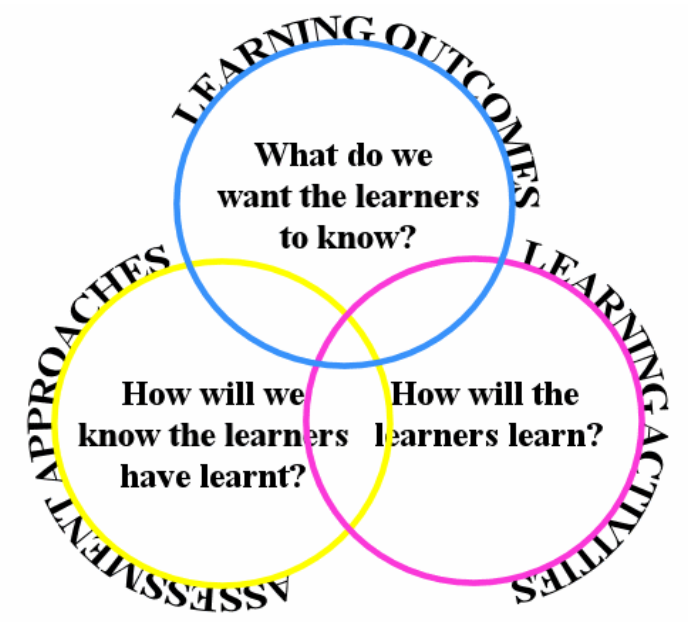

Figure 1. The educational circle arrangement.

Mahmoud Sultan Nafa, MED, Lecturer, City University College of Ajman. 


\section{Why is Assessment a Pivotal Factor in the Educational Process?}

To begin with, assessment is the rational guide that leads and directs the educational process, as it informs teachers and educationalists about the efficacy and the appropriateness of their objectives in terms of their engagement levels or convenience to their learners' educational and social the levels. From another dimension, it shows teachers the proportion or the percentage as well as effectiveness of achieving their goals. Consequently, assessment indicates the points of strengths and motivates educationalists to build on them for further reinforcement and enrichment, as having same level goals and teaching will ultimately lead to plateau effect. This will certainly undermine the educational process as learners will be satisfied and misled in evaluating their educational level, which creates a certain feeling of boredom resulting in misconducts that affects negatively classroom management. Simultaneously, assessment demonstrates the points of weakness and guides teachers to create the convenient remedial works for encountering them as having maltreated points of weakness. Simultaneously, it will lead to a strong feeling of frustration that erupts a sense dissatisfaction causing many classroom management troubles, which cripples the teaching and the learning process.

Furthermore, assessment affects the choice of the teaching and learning techniques, and activities as analyzing assessment tools indicates whether the implemented teaching and learning strategies are appropriate, conducive, or require certain adaptations. If the feedback built on analyzing and the assessment tool shows productive teaching and learning results, educationalists should continue using the implemented teaching and learning techniques whether the feedback shows negative indications educationalists should reflect and adapt on them. They should also carry a comprehensive analysis to find out whether they are below the students' levels or they are more than $\mathrm{i}^{+}$, plus one level that causes destructive frustration which needs prompt well prepared alterations. Furthermore, the virtual use and exploitation of a variety assessment tools compels using multi-leveled teaching and learning techniques, as some assessment techniques oblige using frontal teaching, while others instruct implementing collaborative and communicative teaching and learning techniques. Moreover, effective comprehensive teaching and learning necessitates should consider learning styles, as it requires fostering the visual, auditory, and the kinesthetic learning styles in order to respond to the requirement of different types of assessment.

In another crucial domain, assessment is a corner stone for teachers and learners, as it guides them to decide their best educational course of action. To start with, teachers make use of the analyses and feedbacks drawn from the assessment to evaluate their educational and professional level as well as their professional development needs. If their students are weak in certain points or topics, they have to deliberate rationally on their knowledge of this topic and determine their need for more research on this issue or attending professional development sessions. By contrasts, if the results of the assessment tool indicate that their students excel in a certain area of knowledge, this will give them an incentive for more psychological self-satisfaction and promotion in their career as they may become trainer in this distinguished field. On the other hand, assessment has decisive impacts on learners' learning styles and inclinations as practical feedback of the assessment results will certainly guide students to take principal decision regarding their attitudes toward teaching and learning as well as the educational organization. If the results demonstrate positive and excellent outcomes, they will encourage students to study more in order to excel in this field. Nevertheless, if it indicates weak, low achievements students should find new learning and studying strategies to fill in this gap. 
Simultaneously, assessment has a decisive impact on the leadership of all the educational organizations, as the cold and the hot feedback indications of the assessment tools analyses indicate the success and the type of the leadership and management. If the feedback displays promising results, it indicates a kind of participatory contingent leadership where the parties of the educational organizations are engaged and related and taking open-minded resolutions. Nonetheless, if most results depict below the average achievements, it can be an indication of a despotic one-man or trait type of leadership that takes one dimensional autocratic decisions. Accordingly, assessment can guide the country's policy-maker to evaluate the success and the failure of leadership and management at the educational organizations.

To recapitulate, assessment plays a vital role in guiding, directing, and improving not only the teaching and learning project, but also the whole educational process, as it affects all its parties psychologically and professionally. Furthermore, it can determine the efficacy and the skill as well as the continuity of leaderships and managements at schools.

\section{What is Assessment?}

Assessment can be defined from different points of view due to its comprehensive and multi-leveled perspectives. Firstly, it can be defined as the process of using a diversity of tools to gather information about students' learning outcomes and their achievement levels. William (2011, p.3) defined assessment as "The word assessment describes processes of evaluating the effectiveness of sequences of instructional activities." So, he discussed assessment from a functional point of view. From another perspective, assessment can also be identified as a group of techniques, strategies, or instruments to determine the efficacy or the degree the learners achieve certain pre-prepared and desired objectives. Furthermore, other educationalists, such as Huba and Freed (2000, p. 8) explored assessment comprehensively, as they define its concept and asserting that purpose of implementing tests is to improve the teaching and learning process and to develop students' achievement as they argued:

Assessment is the process of gathering and discussing information from multiple and diverse sources in order to develop a deep understanding of what students know, understand, and can do with their knowledge as a result of their educational experiences. The process culminates when assessment results are used to improve subsequent learning.

Additionally, assessment can be looked at as systematic methods for making academic inferences for students' prospective achievement in order to prepare and carry on the required strategies for improving teaching methodologies and students' attainment. Erwin (1991) investigated the concept of assessment from another perspective as he focused on using all the appropriate tools to check learners' attainment and analyzing them in order to reinforce students learning abilities and their potentials. Accordingly, all the three researchers and three concepts of assessments focuses on evaluating students' attainment and the effectiveness of the teaching and learning in order to find the most convenient ways to improve them.

\section{Types of Assessment}

Due to the high importance of assessment and the diversity of its functions, types of assessment are tackled from different frames of reference. Assessment can be categorized as direct that is through the use of tests, essays, and presentations for checking the lower order thinking skills (LOTS) as some of these methods can be linear or slightly non-linear. On the other hand, assessment tools can be classified as indirect through exploiting surveys and interviews more checking more the higher order thinking skill (HOTS). Both integrated 
assessment tools are high constructive and complementary as they enable educationalists to understand their students' points of strengths and weakness and deal with them appropriately. At the same time, the direct and the indirect methods help teachers and schools' principals to review and adapt the implemented teaching and learning processes as well as the negatively related managerial operations.

From another perspective, Desheng and Varghese (2013) categorized assessment as testing skills, such as the testing of listening, speaking reading, and writing, which comprises certain sub tools, like grammar, comprehension, vocabulary, spelling, and punctuation. On the other hand, knowledge assessment evaluates the educational process, as it provides aptitude and proficiency tests to check students' higher thinking skills.

\section{Types of Assessments}

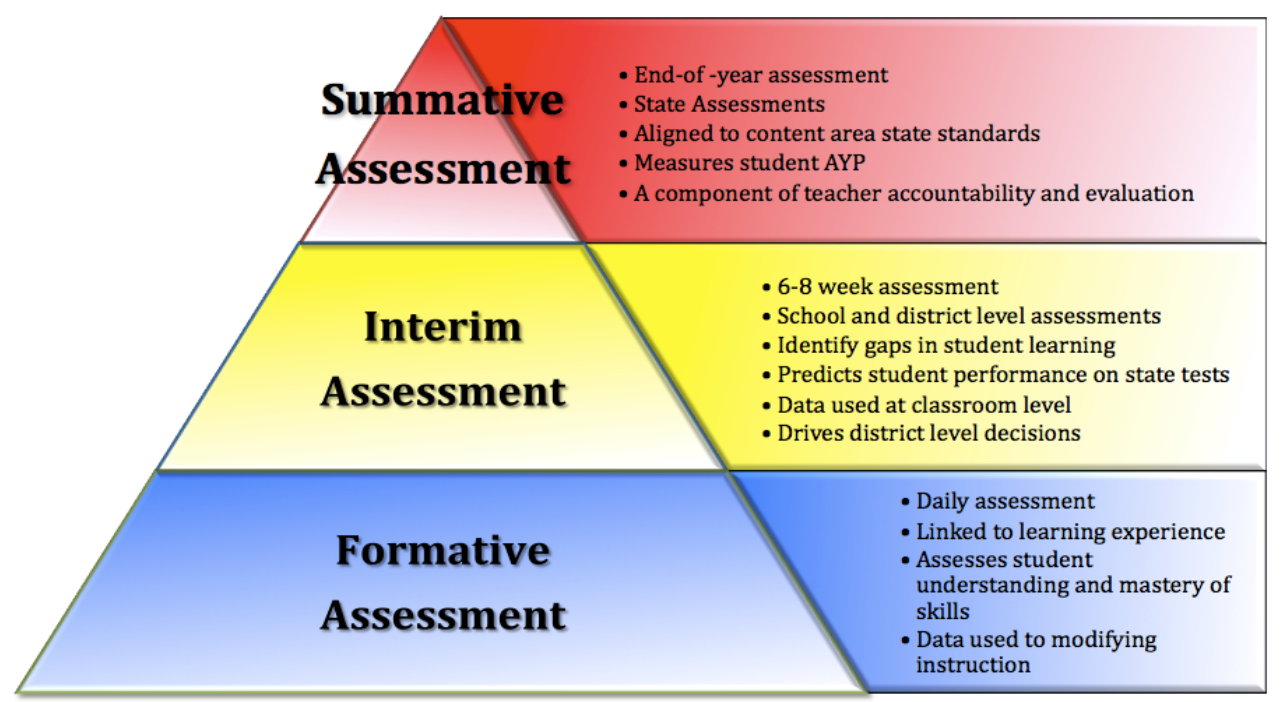

Figure 2. Types of assessment.

\section{Formative Assessment}

Assessment types (see Figure 2) can also be sorted as formative assessment of assessment for learning, which acts an ongoing assessment for guiding and directing the educational process within the course hours. It is the most power assessment tool since it coincides with the educational process and accompanies it, so it helps teachers to reconsider their objectives, teaching methodologies, and classroom management. Regier (2012, p. 5) defined formative assessment as "Formative assessment is a process that uses informal assessment strategies to gather information on student learning. Teachers determine what students understand and what they need to master an outcome.” It can be a series of low-stakes that can start with diagnostic test, series of quizzes, drop in exams, and systematic observations that guide instructors to monitor students' progress, so they are usually quick and easy to fit into the educational process. Blood (2006, p. 57) supported gradual formative assessment as he confirms the graduation principle of starting from the diagnostic test, and then, building on it for correcting and altering the educational process as he affirmed "diagnostic assessment refers to any practice, whether in the form of a formal written test or informal teacher questioning, that yields diagnostic feedback -information on learner strengths and weaknesses.” Furthermore, formative assessment can be as a formal written test an interactive class discussion a warm-up, a closure question, a minute paper, an on-the-spot performance, or a Plus Minus Interesting (PMI) table to evaluate the flow of the educational process. 


\section{Interim Assessment}

Interim assessment is the second and the more developed type of assessment that takes place occasionally and it tends to be more formal as it takes the forms of projects, written assignment, extended essays and end of chapters' tests. The feedback of this type of exam is quick may not be immediate, but learners can make use of it to reconstruct and enrich their potentials. This type of assessment can help teachers to identify the gap between learners' level and the required learning outcomes in order to design the necessary remedial works. Moreover, the interim assessment enables educators to predict students' performance at wider level tests such as the educational zones or states exams; accordingly, it guides them to take the appropriate decisions for improving the students' educational potentials.

\section{Summative Assessment}

Summative assessment is the last level of assessment, which takes place at the end of a certain teaching period, such as the end of the year or a term. Harrison and Howard (2011, p. 21) identified summative assessment as "a means of summing up where a learner, class, school, or country has got to in their learning at a particular point in time.” Moreover, it is called a high stake exam as it evaluates and affects decisively the students' learning, skills acquisition, and promotion in addition to their future prospective plans or careers. It also affects the organizational behaviors of an educational foundation, as it increases its accountability or undermines its academic performance. Consequently, summative assessment is product oriented as it evaluates the outcome of the educational process and it can be in different forms, such as high stakes exams, term papers, portfolios, performances, students' course evaluation, or teachers' self-evaluation. Knight (2002 p. 276) pointed out the importance of summative assessment because it gives academic well organized information to the decision-makers in all aspects of life as he claimed "When assessment certifies achievement it has a feed out function as grades can be treated as a performance indicator for the student, department, institution, employer, funding body, quality agency.” Back et al. (Taras, 2009, p.58.) focused on the vitality of summative evaluation as they call for considering it a part of the overall educational process, although it is carried out at the end of the course or term as it can be used for future studies. Accordingly, they stated "The overall message is that summative tests should be, and should be seen to be, a positive part of the learning process" (Taras, 2009, p. 58.). To recapitulate, summative assessment is the guide that directs teachers, school principals, and area zones directors to know the precise degree of their objectives attainment and the efficacy of their educational policies.

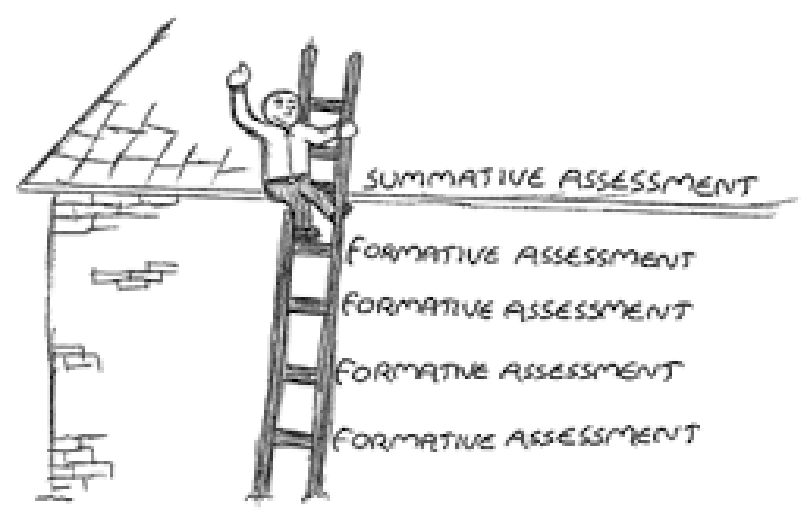

Figure 3. The Build-up of the assessment process. 
Consequently, it is extremely important to distinguish and show the relationship between the formative and the summative assessments. Formative assessment is an integral part of the educational process as it starts and guides it in order to fill in the gap and rectify the errors while teaching, thus it should be followed by quick feedbacks. However, summative assessment comes at the end of the educational process evaluating its successes and shows the points of weaknesses, so its analysis and feedback should be used for future planning. Nevertheless, the formative and the summative assessments play complementary roles as they enrich the whole educational process via their statistical knowledge as shown in figure 3.

\section{What is the Difference Between Assessment and Evaluation?}

There is a major difference between assessment and evaluation as assessment is the gradual process of using a variety of tools for follow up learners' progress, the efficacy of the teaching, and the learning process. On the other hand, evaluation is the final step of judging and estimating the degree of the success of the educational process as well as the ratio of the learners' progress and attainment. It can be summed up as promoting quality or giving a final judging of the quality. Robert Stakes, in Osborne (2013), was quoted as saying, "When the cook tastes the soup, that is formative. When the guests taste the soup, that is summative.” Accordingly, the objective of the formative assessment is reinforce the quality and the summative evaluation is to gage it as shown in figure 4 .

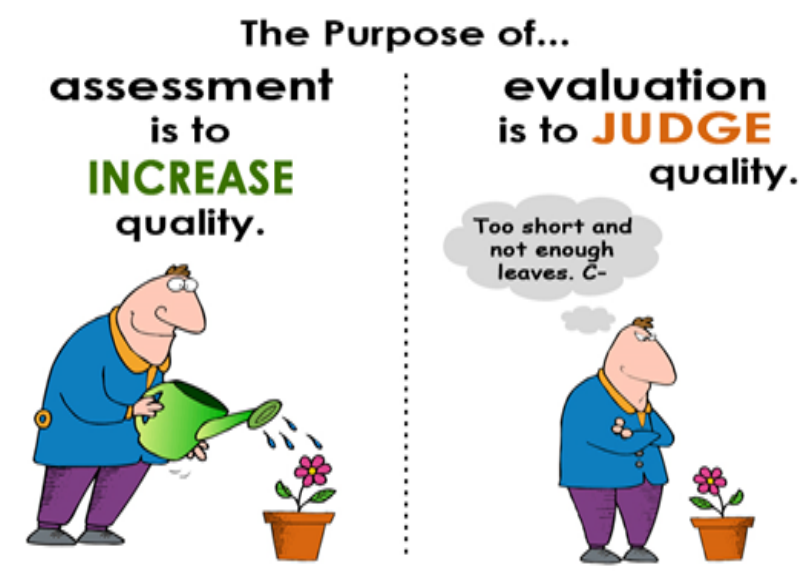

Figure 4. The difference between assessmrnt and evaluation.

\section{The Characteristics of a Constructive Exam}

In order to carry out an effective assessment and evaluation process, there are certain crucial characteristics for a constructive tool that must be observed.

Validity, in its three types, is one of the most pivotal characteristics of an academic exam as it stipulates that a test should measure what it claims to evaluate. Firstly, face validity implies that when having a quick look at the exam, it can be determined if it is valid or not. In other words, if the test is prepared to test vocabulary and it has some items testing grammar, this exam lacks face validity. Thus, teachers should observe the objectives of the exam when preparing it. Curricular or content validity is another crucial quality that is an exam should represent the most important points of the subject matter not only a small portion. However, it is understood that an exam cannot contain the whole materials. Concurrent validity is the third type and it is merely statistical one which requires that the examinees' scores on a small scale is compared with their scores 
on a test of a larger scale, and the results should be approximately identical. For instance, if the students' scores on a vocabulary exam is compared with their scores on wider language exam are at a wide variance, there must be something wrong with one of them.

Reliability is another cornerstone of an effective assessment. It implies a test is independent that is if the same test or a parallel one is administered to students after passing a reasonable time, and the results are nearly identical. Accordingly, reliability is categorized into three basic types: scoring, temporal, and internal reliabilities. Scoring reliability indicates that marking the same exam is consistent if remarked by the same marker or other markers due to the objective score reliability of the exam. The temporal or the test/retest reliability is another guiding key point in forming exam and it states that students' results should be close when students sit for an exam and sitting for an identical exam after a certain period that is not long for getting additional learning. If the grades are not relatively close, there must be something wrong in the test design or the testing process, such as cheating, vague questions, or unclear instructions. Moreover, the internal or split-half reliability is vital key in determining exams efficacy. It is calculated by dividing the questions into two halves of odd and even numbers. If the students' scores on a certain exam are close, then it is identical. However, if there is a wide gap between the students' odd questions scores and even questions scores, the exam does not have internal reliability.

Accordingly, teachers should take certain measures to increase the reliability of their tests. First of all, providing clear-cut instructions of answering the questions on any exam as ambiguous questions weakens the tests' reliability. Additionally, teachers should eliminate or minimize the luck factor by the carefully phrasing their questions or increasing the number of distracters when involving recognition. Furthermore, the exam should be relatively long as it has more variables, so a long exam is more reliable than a short one. Besides, cheating should be strictly forbidden as it not only undermines the exam's reliability, but also undermines the whole educational process. Moreover, blind guessing should be eliminated or reduced to the lowest possible level as it harms the exam consistency by asking learners to explain the reason of their choice or correct wrong answer.

Simultaneously, there are other qualities that improve the efficacy of an exam, such as scorability as a well-constructed exam should be corrected easily and accurately without wasting time or effort. Representativeness is another decisive quality of a professional test as a good test should contain the major elements from all the areas assigned for the exam and must consider the entire learning outcomes. Furthermore, discrimination is an essential requisite for the success of any assessment tool as an exam should mind the individual differences among students. For instance, if most students get more than $80 \%$ or below $30 \%$, the exam must have serious problems on focusing on LOTS by providing linear questions or on HOTS by providing difficult high challenging questions. Additionally, timing is a decisive factor as allotting inadequate or over adequate time can harm the exam's effectiveness as it can lead to low or high scores due to the stress or the cheating factors. In a nutshell, these characteristics are very influential and decisive on the exams design and the whole assessment process.

\section{Preparing a Constructive Test}

Preparing an academic purposeful test requires many academic steps as shown in Figure 5. To start with teachers should determine the objectives of the test in order to preserve its consistency and its function as each item on the exam should be related these objectives. Otherwise, the exam will lose its validity. Moreover, 
teachers should provide adequate time for answer the questions by trying to answering them or asking a colleague to answer them minding that students need triple times of the teacher's answering time. Additionally, teachers should consider including items of different difficulty in order to explore individual differences and to spread students over a wide range of scores. However, it is advisable to place the easier items at the beginning of the exam to encourage students by giving them a sense of achievement and success. Besides, teachers should determine beforehand the weight of the exam in comparison of the final grade and he should inform students previously. Next, teachers should plan the best ways of grading his/her exams and be aware of importance or the weight of each item in the exam and they should show the maximal grade of each question on the exam paper for helping students to manage their time appropriately. Teachers should also provide clear, precise, and direct instruction on the ways to the question as clarity is a crucial issue of test reliability. From another perspective, teachers are to inform students if they decide to penalize for wrong answers so as to minimize blind guessing.

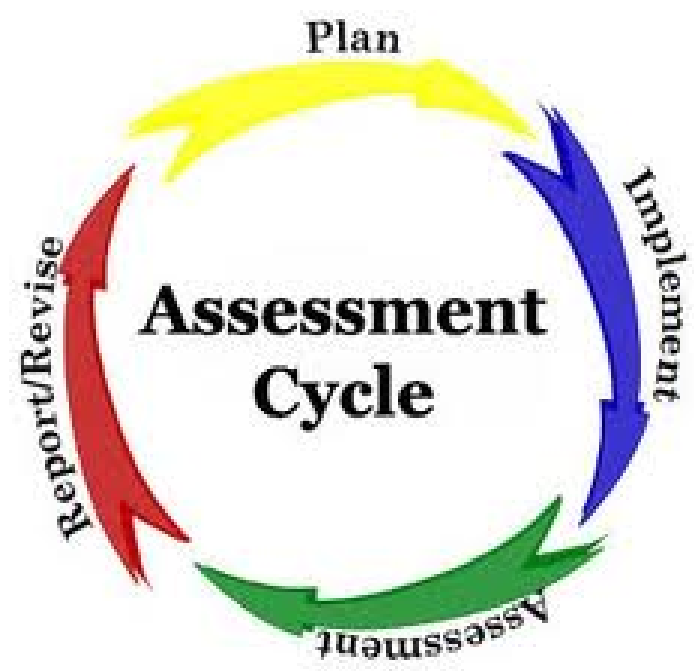

Figure 5. The layout of the assessment process.

\section{Practical Tests Administration Strategies}

Administering a test is also a very crucial step, as it can determine its success or failure which has decisive repercussions on the whole educational process. If the exam is administered probably, it will reflect a truthful feedback that will measure precisely the learning outcomes and will help decision-makers take accurate decisions when dealing with the targeted learners in terms of employment or promotion. Consequently, the following steps should be implemented when administering any test.

1. Giving clear instructions before distributing the exam papers, such as the place and the methods of answering;

2. Other instructions can be given after distributing the papers;

3. Giving students a few minutes to review the exam and ask some questions about the ambiguous items;

4. Prohibiting questions after 20 minutes;

5. Informing students strictly if there are certain penalties for wrong answers;

6. Abstaining from helping students during the exam as teaching should precede or follow the exam as preparation and feedback; and 
7. Insisting on honesty as cheating will not only destroy the validity and the reliability of the exam, but it will certainly harm the whole society as it results in illiterate graduates.

Therefore, the following procedures should be implemented to eliminate or minimize cheating:

1. Spacing students if the size of the room allows;

2. Using different parallel forms of the same exam, and however, they should be identical in content and different in wording;

3. Carrying out different arrangement of the same test in terms of the questions numbers or the distracters;

4. Taking a frontal position with minimal movement rather than moving around students;

5. Reminding troublesome students at the beginning of the exam of the grave consequences of cheating; and

6. Dealing strictly with cheaters as any leniency will undermine the whole teaching and learning process.

\section{Conclusion}

To conclude, assessment is the gauge that guarantees having a highly constructive and purposeful teaching and learning process as it guides, directs, and enriches the entire educational process. Assessment, in its three forms, informs educationalists about the convenience of their objectives, teaching techniques, and classroom managements, and serves a performance indicator of their success. Furthermore, it shows learners the efficacy of their leaning techniques by providing them with precise accurate numbers, thus it helps them to adapt their learning habits, timing, and learning resources as well as their questions types and strategies. Correspondingly, educators should include fully integrated assessment systems of formative, interim, and summative levels in their curricula and courses if they want to secure an effective efficient fruitful educational process.

\section{References}

Blood, I. (2006). Diagnostic second language assessment in the classroom. Teachers College, Columbia University Workings' Papers in TESOL \& Applied Linguistics, 11(1), 57-58.

Desheng, C., \& Varghese, A. (2013). Testing and evaluation of language skills. IOSR Journal of Research \& Method in Education (IOSR-JRME), 1(2), 31-33. Retrieved March 22, 2018, from http://www.iosrjournals.org

Erwin, T. D. (1991). Assessing student learning and development: A guide to the principles, goals, and methods of determining college outcomes. New York, NY: Pearson.

Harrison, C., \& Howard, S. (2011). Issues in primary assessment 3: How summative assessment helps sum up learning. Primary Science, 117, 21-23.

Huba, M. E., \& Freed, J. E. (2000). Learner-centered assessment on college campuses: Shifting the focus from teaching to learning. Boston: Allyn and Bacon.

Kapukaya, K. (2013). Assessment: A help or hindrance to educational purposes. International Journal of Humanities and Social Science, 3(6), 84-93.

Knight, P. (2002). Studies in higher education, 27, 275-286.

Qu, W., \& Zhang, C. (2013). The analysis of summative assessment and formative assessment and their roles in college English assessment system. Journal of Language Teaching and Research, 4(2), 335-339.

Regier, N. (2012). 60 formative assessment strategies (1st ed.). UK: Regier Educational Resources.

Taras, M. (2005). Assessment, summative and formative: Some theoretical reflections. British Journal of Educational Studies, 53(4), 466-478.

Taras, M. (2009). Summative assessment: The missing link for formative assessment. Journal of Further and Higher Education, 33(1), 57-69.

William, D. (2011). What is assessment for learning? Studies in Educational Evaluation, 37(1), 3-14. 